\title{
Analisis Penggunaan Siskeudes dalam Pengelolaan Dana Desa
}

\author{
${ }^{1 *}$ Desy Nur Pratiwi, ${ }^{2}$ Yuwita Ariessa Pravasanti \\ ${ }_{1,2}$ STIE AAS Surakarta, Indonesia \\ *Email korenpondensi: desynurpratiwi362@gmail.com
}

\begin{abstract}
The government provides village funds to improve the welfare of rural communities and equitable development. The purpose of this study was to examine internal and external factors that influence the use of Siskeudes. This study uses primary data in the form of questionnaires and distributed to village fund managers in eight districts in Sukoharjo Regency. The sample collection technique in this study uses convenience sampling method and the total number of samples collected is 32 villages. Hypothesis testing uses multiple linear regression. Partial test results indicate that the variable usefulness (perceived usefulness) and interest in using technology (behavioral intention to use) affect the use of Siskeudes. Simultaneous test results show that the perceived usefulness (perceived usefulness) and interest in using technology (behavioral intention to use) together affect the use of Siskeudes.
\end{abstract}

Keywords: behavioral intention to use, perceived usefulness and Siskeudes

Saran sitasi: Pratiwi, D. N., \& Pravasanti, Y. A. (2020). Analisis Penggunaan Siskeudes dalam Pengelolaan Dana Desa. Jurnal Akuntansi dan Pajak, 20(2), 212-218. doi:http://dx.doi.org/10.29040/jap.v20i2.770

DOI: http://dx.doi.org/10.29040/jap.v20i2.770

1. Pendahuluan

Pemerintahan saat ini memprioritaskan pembangunan desa karena undang-undang desa menempatkan desa sebagai ujung tombak pembangunan. Desa diberikan sumber dana dan kewenangan untuk mengelolanya guna meningkatkan kesejahteraan masyarakat. Pemerintah memberikan dana desa bersumber dari APBN (Anggaran Pendapatan Belanja Negara) dan pemerintah juga merancang berbagai aturan dalam pengelolaan dana desa untuk meningkatkan efisiensi, efektivitas, transaparansi, dan akuntabilitas pemanfaatan dana desa. Rustiarini (2016) menyatakan bahwa dana desa berpotensi untuk meningkatkan kualitas hidup masyarakat desa.

Pemerintah memberikan dana kepada desa dengan jumlah yang cukup besar, sehingga pemerintah juga menuntut pertanggungjawaban pengelolaan dana desa. Oleh karena itu, Pemerintah Desa harus menerapkan prinsip akuntabilitas dalam pengelolaan keuangan desa. semua kegiatan penyelenggaraan pemerintahan desa harus dapat dipertanggungjawabkan kepada masyarakat desa sehingga terwujud tata kelola pemerintahan desa yang baik (Good Village Governance). Haryanto (2007) menyatakan prinsip atau kaidah-kaidah good governance meliputi adanya partisipasi, transparansi dan kebertanggungjawaban dalam pelaksanaan pemerintahan dan pembangunan. Pengelolaan dana desa sebagai bagian dari pelaksanaan pembangunan di desa, sudah seharusnya memegang teguh prinsipprinsip yang merupakan indikator good governance.

Permendes No 3 tahun 2015 tentang pendampingan desa menjelaskan secara luas bahwa setiap desa perlu pendampingan dalam melakukan pengelolaan dana desa. tujuan pemerintah memberikan pendampingan dalam pengelolaan dana desa adalah untuk meningkatkan kapasitas, efektivitas dan akuntabilitas pemerintahan desa dan pembangunan desa; meningkatkan prakarsa, kesadaran dan partisipasi masyarakat desa dalam pembangunan desa yang partisipatif; meningkatkan sinergi program pembangunan antar sektor; dan mengoptimalkan aset lokal desa. 


\section{Jurnal Akuntansi dan Pajak, 20(02), 2019, 218}

Pengelolaan dana desa rawan akan manipulasi sehingga pemerintah telah memberikan aplikasi sistem keuangan desa agar pengelolaan dana desa. Yang mendasari pemerintah membuat aplikasi dana desa yaitu UU Nomor 6 Tahun 2014 tentang Desa. Desa diberikan kesempatan untuk mengurus tata pemerintah sendiri, pengeluaran keuangan dan melakukan pembangunan untuk meningkatkan kesejahteraan dan kualitas hidup masyarakat desa. Aplikasi yang dibangun oleh BPKP (Badan Pengawasan Keuangan dan Pembanguna) dalam pengelolaan dana desa adalah Siskeudes yang telah dikembangkan sejak tahun 2015. Pada tahun 2019 para pengelola keuangan desa dituntut untuk mampu menggunakan aplikasi Siskeudes versi terbaru yaitu Siskeudes 2.0.

Kelebihan aplikasi Siskeudes yaitu memudahkan tata kelola keuangan desa dan dana desa, dilengkapi dengan sistem pengendalian intern, mudah digunakan, berintegrasi dengan aplikasi pengelolaan dana desa lainnya. Kelebihan Siskeudes tersebut juga didukung oleh hasil penelitian Darwin (2017) menunjukkan bahwa implementasi Siskeudes memberikan dampak yang cukup baik dari segi efisiensi waktu dan biaya. Informasi Siskeudes dalam pengelolaan Alokasi Dana Desa dapat menciptakan akuntabilitas pengelolaan Alokasi Dana Desa.

Siskeudes selain mempunyai kelebihan, juga memiliki kekurangan yaitu pengguna/sulit memahami aplikasi Siskeudes karena aplikasi ini masih baru dan sumber daya manusia yang belum familiar dengan aplikasi tersebut sehingga harus mengikuti banyak pelatihan. Hal ini didukung oleh hasil penelitian Afrizal et al. (2016) yang menyatakan bahwa dalam pengelolaan keuangan Desa dengan menggunakan aplikasi Siskeudes terdapat permasalahan berupa belum tersedianya SDM yang memadai dalam menggunakan aplikasi Siskeudes. Hal tersebut sejalan dengan hasil penelitian Siswandi et al (2019) yang menunjukan ada hubungan yang signifikan antara pelatihan komputer dengan efektifitas karyawan di Kecamatan Duren Jaya Bekasi.

Penelitian Siskeudes mulai banyak dilakukan sejak diterapkannya aplikasi Siskeudes pada tahun 2015. Salah satunya penelitian yang dilakukan $\mathrm{Na}$ 'fiah (2018) tentang implementasi dan evaluasi Siskeudes di Provinsi Jawa Timur. Hasilnya menunjukan bahwa Kendala utama implementasi Siskeudes yang dirasakan oleh desa berkaitan dengan SDM desa Evaluasi dari implementasi Siskeudes adalah diperlukan sinergi dari SDM, baik SDM di desa maupun SDM di BPKP sehingga dapat mewujudkan akuntabilitas yang diharapkan. Sehingga, diperlukan pendampingan dari BPKP secara berkelanjutan kepada SDM desa supaya memiliki kompetensi yang cukup dalam mengimplementasikan Siskeudes.

Penlitian lain yang dilakukan oleh Rusmayanti et al (2010) yang menyatakan bahwa sistem informasi mempermudah pihak kantor Desa dalam proses pengelolaan keuangan, membantu dalam proses penginputan data, pencarian data, dan laporan data uang. Sehingga aplikasi Siskeudes dapat meminimalisasi adanya kesalahan dan mengoptimalkan keamanan data. Penelitian yang dilakukan Malahika et al (2018) menunjukan prosedur penggunaan Siskeudes di Desa Suwaan sesuai prosedur, SDM sudah siap melaksanakan Siskeudes, pekerjaan lebih efektif dan efisien dengan Siskeudes.

Penelitian ini bermaksud menganalisis faktor interent dan ekstern dari sumber daya manusia yang mempengaruhi penggunaan aplikasi Siskeudes. Faktor internal yang digunakan oleh penelitian yaitu minat seseorang untuk menggunakan teknologi informasi, sedangkan faktor externalnya yaitu kegunaan dari teknologi informasi akan mendorong pengguna untuk menggunakan aplikasi Siskeudes. Pada penelitian sebelumnya banyak yang membahas pengelolaan dana desa menggunakan aplikasi Siskeudes bukan dari faktor sumber daya manusia yang mempengaruhi penggunaan aplikasi Siskeudes.

Teori yang dijadikan dasar dalam penelitian ini adalah Teechnology Acceptance Model (TAM). TAM menjelaskan hubungan sebab akibat antara keyakinan (manfaat suatu sistem informasi dan kemudahan penggunaannya) dan perilaku, tujuan/keperluan, dan penggunaan aktual dari pengguna/user suatu sistem informasi (Nugroho, 2008). Sehingga model TAM dapat digunakan sebagai dasar menentukan upaya-upaya untuk mendorong kemauan menggunakan teknologi.

Seseorang yang merasakan kemudahan saat menggunakan teknologi informasi untuk menyelesaikan pekerjaannya, maka pengguna akan menggunakan teknologi tersebut. Seperti halnya para pengelola keuangan desa yang merasakan manfaat menggunakan Siskeudes dalam menyusun laporan dana desa maka pengguna akan selalu menggunakan teknologi tersebut. Hal ini didukung 


\section{Jurnal Akuntansi dan Pajak, 20(02), 2019, 219}

oleh penelitian Dewi dan Warmika (2016); Suardikha et al (2012) yang menunjukan bahwa persepsi kegunaan berpengaruh signifikan terhadap penggunaan teknologi inoformasi. Zahid et al (2010) menunjukan persepsi kegunaan merupakan faktor kunci yang mempengaruhi dan memotivasi pengguna untuk menggunakan teknologi.

$\mathrm{H}_{1}=$ Persepsi kegunaan (perceived usefulness) berpengaruh terhadap penggunaan Siskeudes

Seseorang yang mempunyai minat atau ketertarikan pada teknologi akan berusaha meningkatkan kemampuan dengan mengikuti pelatihan dan pendampingan tentang teknologi tersebut. Seperti halnya Siskeudes, para pengguna diberikan pelatihan dan pendampingan agar mahir dalam menggunakannya. Hal tersebut didukung dengan hasil penelitian Pibriana dan Ricoida (2017) yang menunjukan bahwa minat pemanfaatan teknologi informasi berpengaruh terahdap penggunaan teknologi informasi. Hasil penelitian Wairisal dan Khusniah (2012) juga menunjukan minat menggunakan teknologi informasi memiliki kontribusi yang positif dan signifikan terhadap perilaku penggunaan teknologi informasi.

H2: Minat perilaku (Behavioral Intention to Use) berpengaruh terhadap penggunaan Siskeudes

\section{Metode Penelitian}

Penelitian ini dilakukan di delapan Kecamatan pada Kabupaten Sukoharjo yang meliputi Kecamatan Baki, Kecamatan Bendosari, Kecamatan Bulu, Kecamatan Gatak, Kecamatan Grogol, Kecamatan Kartasura, Kecamatan Polokarto dan Kecamatan Weru. Jenis penelitian ini adalah kuantitaif dengan hubungan variabel dependen dan variabel independen. Data yang digunakan penelitian ini adalah data primer yang didapatkan dari penyebaran kuesioner kepada aparatur desa bagian pengelola keuangan desa. Skala yang digunakan dalam kuesioner yaitu skala liker (1-5), nilai 1 menunjukkan sangat tidak setuju dan nilai 5 menunjukkan sangat setuju. Penelitian ini dalam menentukan sampel dengan metode convenience sampling. Menurut Sekaran (2017) convenience sampling adalah kumpulan informasi dari anggotaanggota populasi yang mudah diperoleh dan mampu menyediakan informasi tersebut.

Variabel dependen yang digunakan dalam penelitian ini adalah penggunaan Siskeudes. Variabel independen dalam penelitian ini yaitu minat dan kegunaan teknologi informasi. Pengertian
Siskeudes yaitu aplikasi yang digunakan untuk mengelolaan keuangan desa. Variabel siskeudes ini diukur dengan keinginan pengguna untuk selalu menggunakan aplikasi Siskeudes dimasa yang akan datang. Variabel minat yaitu tingkat keinginan pengguna untuk terus menerus menggunakan teknologi informasi. variabel minat ini diukur dengan Penambahan software pendukung pada teknologi informasi, motivasi penggunaan teknologi informasi, memotivasi kepengguna lain (Muntianah et al., 2012). Sedangkan variabel kegunaan yaitu persepsi seseorang untuk percaya bahwa menggunakan teknologi informasi akan meningkatkan kinerja. Variabel kegunaan diukur dengan dengan efektifitas, menjawab kebutuhan informasi, meningkatkan kinerja dan efisiensi (Muntianah et al., 2012).

Teknik analisis data yang digunakan dalam penelitian ini dengan regresi berganda, berikut persamaan yang digunakan:

Dimana:

$$
\mathrm{Y}=\alpha+\beta_{1} \mathrm{X}_{1}+\beta_{2} \mathrm{X}_{2}+\varepsilon
$$

$$
\begin{array}{ll}
\mathrm{Y} & =\text { Siskeudes } \\
\mathrm{X}_{1} & =\text { kegunaan } \\
\mathrm{X}_{2} & =\text { Minat } \\
\alpha & =\text { konstanta } \\
\beta_{1} \beta_{2} & =\text { koefisiensi regresi } \\
\varepsilon & =\text { eror }
\end{array}
$$

\section{Hasil dan Pembahasan}

Hasil pengumpulan data berupa kuesioner yang dikembalikan dan memenuhi syarat sebagai berikut:

\section{Tabel 1}

Deskripsi Pengumpulan Data

\begin{tabular}{|c|l|c|c|}
\hline No & \multicolumn{1}{|c|}{ Keterangan } & Jumlah & Prosentase \\
\hline 1 & Kuesioner yang disebar & 55 & $100 \%$ \\
\hline 2 & Kuesioner yang kembali & 37 & $67,27 \%$ \\
\hline 3 & $\begin{array}{l}\text { Kuesioner yang tidak } \\
\text { lengkap }\end{array}$ & 5 & $9,09 \%$ \\
\hline 4 & $\begin{array}{l}\text { Jumlah kuesioner yang } \\
\text { diolah }\end{array}$ & 32 & $58,2 \%$ \\
\hline
\end{tabular}

Tabel 1 menunjukan Kuesioner yang disebar di delapan desa Kabupaten Sukoharjo sebanyak 55 desa, namun kuesioner yang kembali hanya 37 desa dan tidak lengkap sebanyak 5 desa. Sehingga jumlah kuesioner yang diolah dalam penelitian ini sebanyak 32 desa.

Jumlah kuesioner tersebut sebelum diolah untuk menjawab hipotesis maka dilakukan pengujian validitas dan reliabilitas untuk pertanyaan yang ada 
di kuesioner. Metode yang dilakukan untuk pengujian validitas dengan melihat pearson corelation masing-masing indikator pernyataan tiap variabel yang digunakan dalam penelitian.

Tabel 2

Uji validitas

\begin{tabular}{|c|l|c|c|c|}
\hline No & Pernyataan & r hitung & r tabel & Validitas \\
\hline 1 & $\mathrm{X} 1.1$ & 0,760 & 0,632 & Valid \\
\hline 2 & $\mathrm{X} 1.2$ & 0,729 & 0,632 & Valid \\
\hline 3 & $\mathrm{X} 1.3$ & 0,630 & 0,632 & Valid \\
\hline 4 & $\mathrm{X} 1.4$ & 0,443 & 0,632 & Valid \\
\hline
\end{tabular}

Tabel 2 merupakan hasil dari uji validitas yang menunjukkan bahwa $r$ hitung $>r$ tabel yang artinya penyataan yang diajukan dalam kuesioner penelitian ini semua valid.

Pengujian reliabilitas dalam penelitian ini dilakukan engan melihat nilai cronbach alpha dimana jika nilai cronvach alfa > 0,60 maka disimpulkan reliabel. Hasil pengujian reliabilitas disajikan pada tabel 3

Tabel 3

Uji reliabilitas

\begin{tabular}{|l|c|c|}
\hline \multicolumn{1}{|c|}{ Variabel } & $\begin{array}{c}\text { Koefisiensi } \\
\text { Alpha }\end{array}$ & Keterangan \\
\hline $\begin{array}{l}\text { Persepsi kegunaan } \\
\text { (Perceived Usefulness) }\end{array}$ & 0,709 & Reliabel \\
\hline $\begin{array}{l}\text { Minat Pengguna } \\
\text { (Behavioral Intention to } \\
\text { Use) }\end{array}$ & 0,642 & Reliabel \\
\hline Penggunaan Siskeudes & 0,620 & Reliabel \\
\hline
\end{tabular}

Tabel 3 pengujian reliabilitas menunjukan bahwa ketiga variabel mempunyai koefisiensi alpha $>0,60$ sehingga dapat disimpulkan bahwa ketiga variabel semua reliabel atau konsisiten.

Setelah melakukan pengujian pada pernyataanpernyataan yang diajukan dalam kuesioner, maka peneliti melakukan pengujian kebaikan data meggunakan uji asumsi klasik. Uji asumsi klasik dalam penelitian ini meliputi uji normalitas, uji heteroskedastisitas dan autokorelasi.

\section{Uji normalitas}

Uji normalitas digunakan untuk mengukur apakah model regresi variabel residual memiliki distribusi normal. Uji normalitas data dalam penelitian ini diukur menggunakan Kolmogrov Smirnov yaitu dengan melihat tingkat signifikansi lebih dari 5\% maka dikatakan normal.
Tabel 4

Uji Nomalitas

\begin{tabular}{|l|l|r|}
\hline & & $\begin{array}{c}\text { Unstandardized } \\
\text { Residual }\end{array}$ \\
\hline $\mathrm{N}$ & Mean & 32 \\
Normal & Std. Deviation & 0,0000000 \\
Parameters & 1,18923355 \\
& Absolute & 0,094 \\
Most Extreme & Positive & 0,053 \\
Differences & Negative & $-0,094$ \\
Kolmogorov-Smirnov Z & 0,529 \\
Asymp. Sig. (2-tailed) & 0,942 \\
\hline
\end{tabular}

Tabel 4 menunjukan bahwa nilai asymp.Sig sebesar 0,942 yang artinya >0,05 sehingga dapat disimpulkan bahwa data dalam penelitian ini terdistribusi normal

\section{Uji Heterokesdastisitas}

Uji heterokedastisitas digunakan untuk mengukur apakah model regresi terjadi ketidaksamaan variance antara residual satu pengamatan dengan pengamatan yang lain. Model regresi yang baik adalah yang tidak terjadi Heteroskedastisitas. Uji heteroskedastisitas dalam penelitian ini menggunakan uji glegser, dengan variabel dependennya berupa abres dan hasil yang dilihat dari nilai sig. $>0,05$.

\section{Tabel 5}

Uji Heterokesdastisitas

\begin{tabular}{|c|c|c|c|c|c|c|}
\hline & \multirow{2}{*}{ Model } & \multicolumn{2}{|c|}{$\begin{array}{l}\text { Unstandardized } \\
\text { Coefficients }\end{array}$} & \multirow{2}{*}{$\begin{array}{c}\text { Standardized } \\
\text { Coefficients }\end{array}$} & \multirow{2}{*}{$\mathrm{t}$} & \multirow{2}{*}{ Sig. } \\
\hline & & B & $\begin{array}{l}\text { Std. } \\
\text { Error }\end{array}$ & & & \\
\hline \multirow{3}{*}{ 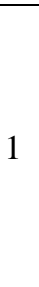 } & (Constant) & $-1,047$ & 1,497 & & $-0,699$ & 0,490 \\
\hline & $\begin{array}{l}\text { Perceived } \\
\text { Usefulness }\end{array}$ & 0,033 & 0,093 & 0,069 & 0,352 & 0,728 \\
\hline & $\begin{array}{l}\text { Behavioral } \\
\text { Intention } \\
\text { to Use }\end{array}$ & 0,117 & 0,096 & 0,240 & 1,216 & 0,234 \\
\hline
\end{tabular}

Tabel 5 menunjukan bahwa nilai sig untuk variabel kegunaan sebesar 0,728 dan variabel minat sebesar 0,234 yang artinya Sig > 0,05 sehingga dapat disimpulkan data yang digunakan dalam penelitian ini tidak terjadi heteroskedastisitas.

\section{Uji Autokorelasi}

Uji autokorelasi digunakan untuk mengetahui hubungan yang terjadi antara residual dengan pengamatan lain. Penelitian ini menggunakan uji Durbin-Watson (DW) dalam melakukan uji autokorelasi. Untuk menentukan terdapat autokorelasi atau tidak jika DL < DW > DU dan DL $<(4-\mathrm{DW})>$ DU. 


\begin{tabular}{|c|c|c|c|c|c|}
\hline & & & $\begin{array}{c}\text { Ju } \\
\text { Tabel } 6 \\
\text { autokorel }\end{array}$ & $\begin{array}{l}\text { rnal Akunt } \\
\text { asi }\end{array}$ & nsi dal \\
\hline Model & $\mathrm{R}$ & $\begin{array}{c}\mathrm{R} \\
\text { Square }\end{array}$ & $\begin{array}{c}\text { Adjusted R } \\
\text { Square }\end{array}$ & $\begin{array}{l}\text { Std. Error of } \\
\text { the Estimate }\end{array}$ & \begin{tabular}{|l|} 
Durbin- \\
Watson
\end{tabular} \\
\hline \begin{tabular}{|l}
1 \\
1
\end{tabular} & $\overline{0,689^{a}}$ & 0,475 & 0,439 & 1,22956 & 1,899 \\
\hline
\end{tabular}

Tabel 6 menunjukan bahwa nilai DW sebesar 1,899 dengan jumlah sampel (n) sebanyak 32 dan 2 variabel independen. Tabel DW pada $\alpha 5 \%$ maenunjukan nilai $\mathrm{dL}=1,4073$ dan $\mathrm{dU}=1,6061$ sehingga dapat disimpulkan nilai $\mathrm{dL}<\mathrm{DW}>\mathrm{dU}$ yang artinya tidak terdapat autokorelasi.

\section{Uji Koefisiensi Determinasi}

Uji koefisiensi determinasi digunakan untuk mengetahui baik buruknya data yang digunakan penelitian.

\section{Tabel 7}

Uji Koefisiensi Determinasi

\begin{tabular}{|l|c|r|r|r|}
\hline Model & $\mathrm{R}$ & $\begin{array}{c}\mathrm{R} \\
\text { Square }\end{array}$ & $\begin{array}{c}\text { Adjusted R } \\
\text { Square }\end{array}$ & $\begin{array}{c}\text { Std. Error of } \\
\text { the Estimate }\end{array}$ \\
\hline 1 & $0,689^{\mathrm{a}}$ & 0,475 & 0,439 & 1,22956 \\
\hline
\end{tabular}

Tabel 7 menunjukkan bahwa nilai Adjusted R Square 0,439 yang artinya variabel independen dalam penelitian ini mempengaruhi variabel dependen sebesar $43,90 \%$ dan $56,10 \%$ dipengaruhi variabel lain diluar variabel independen dalam penelitian ini.

\section{Uji Statistik F}

Uji statistik F ini disebut juga uji simultan yang digunakan untuk mengetahui pengaruh variabel independen secara simultan/bersama-sama berpengaruh terhadap variabel depeden. Uji statistik F dilihat dari nilai Sig. $<0,05$ maka disimpulkan terdapat pengaruh simultan variabel independen terhadap variabel dependen.

\section{Tabel 8}

Uji Statistik F

\begin{tabular}{|c|c|c|c|c|c|c|}
\hline \multicolumn{2}{|r|}{ Model } & $\begin{array}{l}\text { Sum of } \\
\text { Squares }\end{array}$ & df & \begin{tabular}{c|} 
Mean \\
Square
\end{tabular} & $F$ & Sig. \\
\hline \multirow{3}{*}{1} & Regression & 39,626 & 2 & 19,813 & 13,106 & 0,000 \\
\hline & Residual & 43,843 & 29 & 1,512 & & \\
\hline & Total & 83,469 & 31 & & & \\
\hline
\end{tabular}

Tabel 8 menunjukan bahwa nilai Sig. yaitu 0,000 yang berarti $<0,05$ sehingga dapat disimpulkan bawa variabel kegunaan dan minat secara bersama-sama berpengaruh terhadap pengunaan Siskeudes.
Pengujian

Pengujian Hipotesis

\begin{tabular}{|c|c|c|c|c|c|c|}
\hline \multicolumn{7}{|c|}{$\begin{array}{c}\text { Tabel } 9 \\
\text { Uji t }\end{array}$} \\
\hline & \multirow[b]{2}{*}{ Model } & $\begin{array}{r}\text { Unstand } \\
\text { Coeffic }\end{array}$ & $\begin{array}{l}\text { rdized } \\
\text { ients }\end{array}$ & $\begin{array}{c}\text { Standardized } \\
\text { Coefficients }\end{array}$ & \multirow[b]{2}{*}{$\mathrm{t}$} & \multirow[b]{2}{*}{ Sig. } \\
\hline & & B & $\begin{array}{c}\text { Std. } \\
\text { Error }\end{array}$ & Beta & & \\
\hline \multirow{3}{*}{1} & (Constant) & $-0,839$ & 2,405 & & $-0,349$ & 0,730 \\
\hline & $\begin{array}{l}\text { Perceived } \\
\text { Usefulness }\end{array}$ & 0,354 & 0,149 & 0,353 & 2,369 & 0,025 \\
\hline & $\begin{array}{l}\text { Behavioral } \\
\text { Intention to } \\
\text { Use }\end{array}$ & 0,477 & 0,154 & 0,460 & 3,090 & 0,004 \\
\hline
\end{tabular}

Tabel 9 menunjukan bahwa nilai sig variabel kegunaan (Perceived Usefulness) 0,025 $<0,05$ yang berarti bahwa perceived usefulness berpengaruh terhadap penggunaan aplikasi Siskeudes $\left(\mathrm{H}_{1}\right)$ diterima. Hasil ini dapat dijelaskan bahwa sebagian besar responden merasakan manfaat dari penggunaan Siskeudes yaitu meningkatkan produktivitasnya dalam bekerja sehingga responden akan selalu menggunakan aplikasi Siskeudes dimasa yang akan datang. Hal tersebut didukung dengan hasil penelitian Dewi dan Warmika (2016); Fadhil dan Fachruddin (2016) yang menunjukan persepsi manfaat berpengaruh positif dan sigmifikan terhadap mobile commerce di Bali. Sejalan juga dengan penelitian Suardikha et al (2012) yang menyatakan persepsi kegunaan berpengaruh sigifikan terhadap penggunaan sistem informasi akuntansi. Hasil penelitian Zahid et al (2010) menunjukan persepsi kegunaan merupakan faktor kunci yang mempengaruhi dan memotivasi pengguna untuk menggunakan teknologi.

Tabel 9 menunjukan nilai sig variabel minat (Behavioral Intention to Use) sebesar 0,004 < 0,05 yang berarti variabel minat berpengaruh terhadap penggunaan Siskeudes $\left(\mathrm{H}_{2}\right)$ diterima. hasil ini dijelaskan bahwa seseorang yang dari awal sudah tertarik untuk menggunakan Siskeudes dan mengikuti pelatihan serta pendampingan maka akan meningkatkan minat dalam menggunakan aplikasi tersebut. Hal tersebutlah yang mendorong sebagain besar responden menggunakan aplikasi Siskeudes dalam pengelolaan dana desa. Hasil penelitian ini sejalan dengan Pibriana dan Ricoida (2017); menunjukan minat pemanfaatan teknologi informasi berpengaruh positif terhadap penggunaan teknologi informasi. Hasil penelitian Wairisal dan Khusniah (2012) juga menunjukan minat menggunakan teknologi informasi memiliki kontribusi yang positif dan signifikan terhadap perilaku penggunaan teknologi informasi. 


\section{Kesimpulan}

Penelitian ini bertujuan menguji faktor internal dan eksternal yang berpengaruh terhadap penggunaan aplikasi sikeudes. Hasil pengujian ini secara parsial menunjukan bahwa persepsi kegunaan (perceived usefulness) dan minat (Behavioral Intention to Use) berpengaruh terhadap penggunaan aplikasi Siskeudes. Hasil pengujian secara parsial variabel kegunaan dan minat secara bersama-sama berpengaruh terhadap penggunaan aplikasi Siskeudes.

Keterbatasan penelitian ini yaitu nilai adjusted $\mathrm{R}^{2}$ dalam penelitian ini sebesar 0,439 atau $43,90 \%$ yang berarti variabel persepsi kegunaan (perceived usefulness) dan variabel minat menggunakan teknologi mempengaruhi penggunaan aplikasi Siskeudes hanya sebesar $56,1 \%$ dipengaruhi varibael lain diluar variabel kegunaan dan minat. Sehingga saran bagi peneliti berikutnya untuk menambahkan variabel lain.

\section{Ucapan Terima Kasih}

Kami ucapkan terimakasih kepada Direktorat Riset dan Pengabdian Masyarakat (DRPM) Dikti yang telah memberikan dana penelitian dan Lembaga Penelitian dan Pengabdian kepada Masyarakat (LPPM) STIE AAS Surakarta atas segala dukungan dan bantuannya dalam menyelesaikan penelitian ini.

\section{Daftar Pustaka}

Afrizal, Mazaliza, Z., dan Khudri, A. (2016). Analisis Prosedur Pengelolaan Keuangan Desa Sungai Pinang Melalui Aplikasi Siskeudes. (12), 1-8

Darwin. (2017). Aplikasi Sistem Informasi Manajemen Daerah (Simda) Dalam Menciptakan Akuntabilitas Pengelolaan Alokasi Dana Desa ( Add ) Di Kabupaten Sinjai Regional. Universitas Hasanuddin.

Dewi, N. M. A. P., dan Warmika, I. G. K. (2016). Peran Persepsi Kemudahan Penggunaan, Persepsi Manfaat dan Persepsi Resiko terhadap Niat Menggunakan Mobile Commerce di Kota Denpasar. E-Jurnal Manajemen, 5(4).

Fadhil, M., \& Fachruddin, R. (2016). Pengaruh Persepsi Nasabah Atas Risiko, Kepercayaan, Manfaat, dan Kemudahan Penggunaan terhadap Penggunaan Internet Banking (Studi Empiris pada Nasabah Bank Umum di Kota Banda Aceh). Jurnal Ilmiah Mahasiswa Ekonomi Akuntansi, 1(2), 264-276. ak, 20(02), 2019, 222

Haryanto, Sahmuddin. (2007). Akuntansi Sektor Publik. Edisi Pertama, Universitas Diponegoro, Semarang

Malahika, J. M., Karamoy, H., dan Pusung, R. J. (2018). Penerapan Sistem Keuangan Desa (Siskeudes) Pada Organisasi Pemerintahan Desa (Studi Kasus Di Desa Suwaan Kecamatan Kalawat Kabupaten Minahasa Utara). Jurnal Riset Akuntansi Going Concern, 13(04).

Nafi'ah, N. K. (2018). Implementasi Dan Evaluasi Sistem Keuangan Desa (Siskeudes) Di Provinsi Jawa Timur (Doctoral dissertation, Universitas Brawijaya).

Nugroho, Eko. (2008). Sistem Informasi Manajemen. Yogyakarta: Andi Publisher

Peraturan Menteri Dalam Negeri No. 20 Tahun 2018 tentang pengelolaan keuangan desa.

Peraturan Pemerintah No 60 Tahun 2014 Tentang Dana Desa Yang Bersumber Dari Anggaran Pendapatan Dan Belanja Negara.

Permendagri Nomor 113 Tahun 2014 Tentang Pedoman Pengelolaan Keuangan Daerah

Pibriana, D., dan Ricoida, D. I. (2017). Analisis Pengaruh Penggunaan Internet Terhadap Minat Belajar Mahasiswa (Studi Kasus: Perguruan Tinggi di Kota Palembang). JATISI (Jurnal Teknik Informatika dan Sistem Informasi), 3(2), 104-115.

Rusmayanti, A., Purnama, B. E., dan Sukadi. (2010). Sistem Informasi Pengelolaan Keuangan. Indonesian Journal on Computer Science Speed. 1979-9330, 1-5.

Rustiarini, Ni Wayan. (2016). Good Governance Dalam Pengelolaan Dana Desa. Simposium Nasional Akuntansi, 1-18.

Sanjaya, I. P. S. (2017). Pengaruh Rasa Manfaat Dan Kemudahan Terhadap Minat Berperilaku (Behavioral Intention) Para Mahasiswa Dan Mahasiswi Dalam Penggunaan Internet. Jurnal Kinerja, 9 (2), 113-122.

Siswandi, S., Narpati, B., dan Gofur, A. (2019). Making Work Effectiveness In Kelurahan Duren Jaya Bekasi Jawa Barat. International Journal of Economics, Business and Accounting Research (IJEBAR), 3(04), 307319. 
Jurnal Akuntansi dan Pajak, 20(02), 2019, 223

Suardikha, I. M. S., Sutrisno, T., Sukoharsono, E., dan Purnomosidhi, B. (2012). Pengaruh Implementasi Budaya Tri Hita Karana Terhadap Penggunaan Sistem Informasi Akuntansi dimediasi Keyakinan-diri atas Komputer, Keinovatifan Personal, Persepsi Kegunaan, dan Persepsi Kemudahan Penggunaan pada Bank Perkreditan Rakyat di Bali. Disertasi. Program Doktor Ilmu Akuntansi, Program Pascasarjana Falkultas Wairisal, L. P., dan Khusniyah, N. (2012). Analisis Perilaku Penggunaan Teknologi Informasi (Studi pada Dosen Universitas Pattimura Ambon). Jurnal aplikasi manajemen, 10(4), 761-771.

Zahid, N., Mujtaba, A., dan Riaz, A. (2010). Consumer acceptance of online banking. European Journal of Economics, Finance and Administrative Sciences, 27(1), 44-52

Ekonomi dan Bisnis Universitas Brawijaya Malang. 